for unmarried males (0.103 to 1.206$)$, and the largest variability in variances was among unmarried females (0.000 to 1.994).

Conclusion Robust fits of our model to the empirical sexual behaviour data suggest that non-cohabiting sex partnering appears to be a random "opportunistic" phenomenon. Unmarried individuals have larger means than their married counterparts, and males have larger means than females. Unmarried individuals appear to play a key role in driving heterogeneity in sexual networks and STIs epidemiology.

Disclosure of interest statement No pharmaceutical grants were received in the development of this study.

\section{P04.12 FRONT-TO-BACK WIPING AND DABBING BEHAVIOUR WIPING POST-TOILET SIGNIFICANTLY ASSOCIATED WITH ANAL NEOPLASIA AND HR-HPV CARRIAGE IN A COHORT OF WOMEN WITH A HISTORY OF AN HPV- MEDIATED GYNAECOLOGICAL NEOPLASIA}

${ }^{1}$ Steve Simpson*, 2,3Penny Blomfield, ${ }^{4}$ Amanda Dennis, ${ }^{5}$ Sepehr Tabrizi, ${ }^{1,3}$ Richard Turner. ${ }^{1}$ Menzies Institute for Medical Research, University of Tasmania, Hobart Australia; ${ }^{2}$ Gynaecologic Oncology, Royal Hobart Hospital, Hobart, Australia; ${ }^{3}$ School of Medicine, University of Tasmania, Hobart, Australia; ${ }^{4}$ Gynaecologic Oncology, Launceston General Hospital, Launceston, Australia; ${ }^{5}$ Department of Microbiology and Infectious Diseases, The Royal Women's Hospital, Parkville, Australia; ${ }^{6}$ School of Medicine, University of Tasmania, Hobart, Australia

\subsection{6/sextrans-2015-052270.266}

Background Anal cancer is an HPV-mediated neoplasia of the squamous epithelium of the anus. A hitherto unexplained feature of anal cancer epidemiology is its much higher frequency among women, who comprise nearly two thirds of cases.

Methods Cross-sectional study of women with a history of an HPV-mediated gynaecological neoplasia in Tasmania, Australia. Women presenting for follow-up gynaecological care had anal swab samples taken for anal cytology by Hologic Liquid ThinPrep and HR-HPV typing. Women with abnormal anal cytology were invited for high-resolution anoscopy (HRA). Covariates of anal outcomes evaluated by log-binomial and log-multinomial regression.

Results 163 women had anal swabs taken and comprised the study sample, of whom $40.0 \%$ had abnormal cytology $(28.2 \%$ high-grade). Of the 50 women with abnormal anal cytology having an HRA, $64.0 \%$ had abnormal histology (26.0\% high-grade). Of the 120 women having anal HPV typing done, $31.7 \%$ had HR-HPV carriage, the most common types being 51 (11.5\%) and $16(9.2 \%)$.

In addition to some known anal cancer risk factors, we found front-to-back (FTB) wiping was associated with significantly increased prevalence of cytological and histological abnormality and HR-HPV carriage, while dabbing post-toilet was significantly decreased prevalences of all anal outcomes, all robust to adjustment.

Conclusions We have shown here that post-toilet wiping behaviours, specifically FTB and dabbing, significantly modulated the prevalence of anal cytological, histological and HR-HPV carriage outcomes. While the cross-sectional design precludes ascription of causality, the biological plausibility of such an autoinoculation pathway might help explain the preponderance of anal cancer among women.

Conflicts of interest We have no conflicts to disclose.

\section{P04.13 THE SEXUAL HEALTH LITERACY OF THE STUDENT POPULATION OF THE UNIVERSITY OF TASMANIA: RESULTS OF THE RUSSL STUDY}

${ }^{1}$ Steve Simpson* ${ }^{2}$ Christine Clifford, ${ }^{3}$ Kaz Ross, ${ }^{4}$ Neil Sefton, ${ }^{5}$ Louise Owen, ${ }^{1}$ Leigh Blizzard, ${ }^{1,4}$ Richard Turner. 'Menzies Institute for Medical Research, University of Tasmania, Hobart Australia; ${ }^{2}$ School of Psychology, University of Tasmania, Hobart Australia; ${ }^{3}$ School of Humanities, University of Tasmania, Hobart Australia; ${ }^{4}$ School of Medicine, University of Tasmania, Hobart Australia; ${ }^{5}$ Sexual Health Service Tasmania, Tasmanian Department of Health and Human Services, Hobart Australia

\section{$10.1136 /$ sextrans-2015-052270.267}

Introduction/background/issues Evidence suggests a varied level of sexual health literacy (SHL) among university student populations. Accordingly, we evaluated the SHL among students at the University of Tasmania.

Methods Students were invited to complete an anonymous online questionnaire.

Recruitment was during August/September 2013. SHL was assessed by ARCSHS National Survey of Australian Secondary Students and Sexual Health and the Sexual Health Questionnaire. Predictors of literacy scores were evaluated by linear regression.

Results/discussions The study recruited 1,786 participants, or $8.2 \%$ of the student population, of similar composition to the general university population.

Female sex, older age, and sexual education and increased communication on sexual topics were significant predictors of literacy scores. Literacy increased with sexual experience (ever sex, earlier age of sexual debut, partner number, diversity of sexual activity). Students in medical/nursing disciplines had the highest SHL.

Compared to Australian/New Zealander students, overseasborn students had significantly lower ARC $(-3.6 \%, \mathrm{p}<0.001)$ and SHS $(-4.2 \%, \mathrm{p}<0.001)$, this driven by Malaysian, Indian and Chinese students. Compared to agnostic/atheist-identifying students, those of Buddhist (ARC: $-5.4 \%, p=0.014$; SHS: $6.7 \%, \mathrm{p}=0.002$ ), Muslim (ARC: $-16.5 \%, \mathrm{p}<0.001$; SHS: $13.4 \%, \mathrm{p}=0.001$ ) and Protestant (ARC: $-2.3 \%, \mathrm{p}=0.023$; SHS: $-4.4 \%, \mathrm{p}<0.001)$ identifications had markedly lower SHL. Importantly, many of these associations persisted on adjustment for age, sex, sexual education and sexual experience.

Conclusions/implications This study, one of the first targeting among university students in Australia, found a varied SHL by sex, age, sexual education and sexual experience, as well as by birthplace and religious affiliation. These findings have applications in orientation and education programs at Australian universities.

Key message This study substantiates the ongoing deficits in sexual health literacy in some minority religious/ethnic/birthplace populations, suggesting some role for remedial sexual health education in university orientation programs may be appropriate.

\section{P04.14 PREVALENCE AND CONSISTENCY OF OPINIONS ON SAME-SEX PARTNERSHIPS OVER 12 YEARS IN A NEW ZEALAND BIRTH COHORT}

${ }^{1} \mathrm{~J}$ Connor, ${ }^{2} \mathrm{E}$ Burgess, ${ }^{2} \mathrm{~J}$ Cresswell, ${ }^{1} \mathrm{~A}$ Righarts, ${ }^{1} \mathrm{~N}$ Dickson. ${ }^{2}$ Department of Preventive and Social Medicine, University of Otago, Dunedin, New Zealand; '² London School of Hygiene and Tropical Medicine, London, UK

10.1136/sextrans-2015-052270.268 